\title{
0 atendimento educacional de pessoas com Síndrome de Down no Estado do Pparaná em contraponto com a Política Nacional de Educação Especial na perspectiva da Educação Inclusiva
}

DOI: https://doi.org/10.35168/2176-896X.UTP.Tuiuti.2021.Vol7.N63.pp23-36

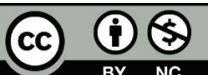

Bruno Beatriz bruno_beatriz@zipmail.com.br Larissa Gabriele Ogliari Thomazi larissaogliari@hotmail.com Patrícia Verona de Freitas patifm@hotmail.com

Edna Alves Ferreira edna_dipaula@hotmail.com 


\section{0 atendimento educacional de pessoas com Síndrome de Down no Estado do Pparaná em contraponto com a Política Nacional de Educação Especial na perspectiva da Educação Inclusiva}

\section{Resumo}

A presente pesquisa versa sobre o atendimento educacional para pessoas com Síndrome de Down de 04 a 17 anos no estado do Paraná em vias de encontro com a política de educação especial dos demais estados da federação na perspectiva da educação inclusiva.

Palavras-chave: Síndrome de Down. Educação especial. Inclusão. 


\section{0 atendimento educacional de pessoas com Síndrome de Down no Estado do Pparaná em contraponto com a Política Nacional de Educação Especial na perspectiva da Educação Inclusiva}

As pesquisas e estudos da área da biologia apontam que as células do corpo humano são formadas por 46 cromossomos, sendo eles 44 do tipo autossômicos, ou seja, com sua bagagem genética, sendo iguais para homens e mulheres, e mais dois cromossomos sexuais. Os últimos são representados por letras (X e Y), e responsáveis por representar o sexo do indivíduo.

Portanto, a carga genética humana é expressa por 44 cromossomos idênticos 2 a 2, formando 22 pares de componentes genéticos no interior das células, mais o par sexual composto de XX para mulheres e XY para homens, num total de 23 pares cromossômicos.

Com a fecundação e o início das divisões celulares da célula ovo, para que ocorra o crescimento de um novo ser, alguns acidentes genéticos podem ocorrer, e, tem-se na literatura que uma das alterações mais comuns na espécie humana é o excesso de carga genética.

Quando essa alteração genética se dá com o acréscimo de um filamento de cromossomo no par 21, ocasiona a Síndrome de Down. Esta ocorrência também é chamada de Trissomia do 21, como descreve Werneck: No caso específico do portador da Síndrome de Down há um cromossomo a mais no par 21. Este cromossoma é o responsável por todas as anomalias atribuídas à síndrome. (1992, p. 42).

As anomalias citadas pela autora dizem respeito as características típicas dos indivíduos que nascem com esta mutação genética. Além de questões físicas peculiares, a presença do cromossoma extra no par 21 ocasiona mudanças comportamentais, uma vez que as pessoas com a mutação genética apresentam atrasos em seu desenvolvimento global. 


\section{0 atendimento educacional de pessoas com Síndrome de Down no Estado do Pparaná em contraponto com a Política Nacional de Educação Especial na perspectiva da Educação Inclusiva}

Em razão do excesso de material cromossômico, provocado pelo acidente genético, várias reações químicas essenciais pelo bom desempenho dos sistemas do organismo não se fazem de forma apropriada. Há, ainda, diferenças quanto ao tamanho do cérebro e do número de neurônios nos casos de Síndrome de Down. Além dessas razões de ordem biológica, outros fatores de ordem ambiental, podem exacerbar ou diminuir os possíveis prejuízos. A presença de complicações clínicas (cardiopatias, infecções crônicas, perda auditiva, etc) também podem dificultar um desenvolvimento mais adequado. (WERNECK, 1992, p.34)

Entretanto, o desenvolvimento cognitivo e a aquisição de habilidades intelectuais por parte das crianças afetadas pela Síndrome de Down sofrem grande variação de um indivíduo ao outro, oscilando de deficiente mental severo em alguns casos à inteligência muito próxima do normal, em outros.

Embora em um ritmo mais lento, estas ocorrências podem ser perfeitamente reversíveis e/ ou atenuadas quando a criança Down é submetida a um atendimento específico, estimulando o desenvolvimento pleno de suas capacidades próprias. Sobre este ponto de vista Canning e Pueschel exemplificam:

Se na criança "normal" a aprendizagem de tais atividades exige uma boa parcela de prática e experiência, quanto mais trabalho, paciência e treinamento não serão necessários para a criança com Síndrome de Down! Esta criança tem que ultrapassar um grande número de obstáculos que desaceleram o ritmo de sua aquisição de habilidades [...] (2003, p. 17). 


\section{0 atendimento educacional de pessoas com Síndrome de Down no Estado do Pparaná em contraponto com a Política Nacional de Educação Especial na perspectiva da Educação Inclusiva}

Torna-se importante ressaltar que as etapas de desenvolvimento são as mesmas em indivíduos com Trissomia 21 ou não, ocorrendo apenas em um ritmo mais lento, como foi afirmado anteriormente. Nesta perspectiva, "vale observar que enquanto um ser humano normal atinge seu desenvolvimento pleno no final da adolescência (18 anos em média), os portadores da síndrome de Down só o fazem por volta dos 30 anos”. (WERNECK, 1992, p. 54).

Entende-se, portanto, que as interferências do ambiente em que a criança cresce são fatores decisivos para minimizar os atrasos de desenvolvimento, e, que neste mesmo viés, a importância da educação escolar para os seres humanos e a vida em sociedade é algo inquestionável, afinal, todos nós resultamos de fatores e vivências biológicas e sociais experimentadas ao longo da vida.

Pode-se afirmar, também, que o processo de escolaridade, os termos e condições que essa vivência é posta, é fator fundamental e que contribui para a conquista do desenvolvimento cognitivo, social e comportamental dos seres humanos, independentemente de qualquer condição biológica.

Portanto, o investimento no processo de escolaridade formal e na consequente alfabetização de deficientes intelectuais, e, por consequência pessoas com Síndrome de Down, é prematuro e busca sua consolidação no cenário educacional atual. Este é um investimento árduo, afinal:

(...) as crianças retardadas, quando deixadas a si mesmas, nunca atingirão formas bem elaboradas de pensamento abstrato, é que a escola deveria fazer todo esforço para empurrá-las nesta direção, para desenvolver nelas o que está intrinsecamente faltando no seu próprio desenvolvimento. (VYGOTSKY, p. 116, 1989). 


\section{0 atendimento educacional de pessoas com Síndrome de Down no Estado do Pparaná em contraponto com a Política Nacional de Educação Especial na perspectiva da Educação Inclusiva}

Pelo pensamento de Vygotsky, as crianças com deficiência intelectual se estimuladas de forma eficaz, inseridas em rico ambiente cultural, podem atingir níveis elevados de escolaridade e funções psicológicas superiores.

Diante dos ensinamentos de Vygotsky e de tantos outros autores, percebe-se que oferecer uma educação de qualidade aos estudantes, está muito além de garantir sua matrícula no sistema público de ensino, principalmente quando estamos pensando em alunos com Trissomia do Cromossomo 21 e, por consequência deficiência intelectual.

Tem-se, ainda, que, ao analisar o perfil do atendimento educacional destinado às pessoas com deficiência no Brasil, num prisma eminentemente histórico, o que se mostra de forma mais evidente é a atuação de instituições filantrópicas, assistencialistas ou especializadas seja nas áreas de deficiência intelectual, visual, física ou da surdez, em atendimentos separados dos bancos escolares regulares, voltados às pessoas ditas com desenvolvimento típico.

Esta exclusão escolar, que cruelmente culminou numa exclusão também social, se deu devido ao fato de que, segundo Pan (2004), até os anos 50 do referido século, as deficiências eram consideradas a partir de um enfoque inatista, onde pouca ou nenhuma credibilidade na mudança do quadro patológico era depositada. Somando-se a isso, pesava ainda que os déficits eram considerados irreversíveis e imutáveis.

Verifica-se, ao exposto, que a real atenção aos educandos especiais é de época recente. Isto porque foi dada de forma muito lenta e a educação especial brasileira carrega "historicamente as marcas da descontinuidade, da filantropia e do assistencialismo". (MOREIRA, BAUMEL, 2001, p. 3) 


\section{0 atendimento educacional de pessoas com Síndrome de Down no Estado do Pparaná em contraponto com a Política Nacional de Educação Especial na perspectiva da Educação Inclusiva}

Entende-se, neste estudo, que a prática de uma educação de qualidade, emancipatória e que proporcione qualidade de vida aos estudantes tem como fundamento os princípios políticos de sua oferta, em seu conjunto de leis, decretos e regulamentações propostas pelo poder público para o oferecimento deste serviço.

Considerando o repertório legal nacional, tem-se a organização da educação básica no Brasil fundamentada já na carta magna, Constituição Federal, que, em seu artigo Art. 205 faz previsão: A educação, direito de todos e dever do Estado e da família, será promovida e incentivada com a colaboração da sociedade, visando ao pleno desenvolvimento da pessoa, seu preparo para o exercício da cidadania e sua qualificação para o trabalho. (BRASIL, 1989).

A presença da previsão legal da educação pública e obrigatória neste documento é um importante passo na universalização deste serviço que deve ser oferecido de forma gratuita e obrigatória à toda população de 4 a 17 anos. Assim, Cury e Ferreira reconhecem:

A atual Constituição Federal de 1988 apresentou um marco significativo no encaminhamento dos problemas relativos à educação brasileira, posto que estabeleceu diretrizes, princípios, normas que destacam a importância que o tema merece. Reconheceu a educação como "um direito social e fundamental, possibilitando o desenvolvimento de ações por todos aqueles responsáveis pela sua concretização, ou seja, o Estado, a família, sociedade e a escola (educadores)" (FERREIRA, 2008, p.37), bem como concebeu como um direito público subjetivo, assim compreendido como a faculdade de se exigira prestação prometida pelo Estado. ((CURY e FERREIRA, 2010, p, 75) 


\section{0 atendimento educacional de pessoas com Síndrome de Down no Estado do Pparaná em contraponto com a Política Nacional de Educação Especial na perspectiva da Educação Inclusiva}

Depois deste importante avanço judicial do século XX na legislação educacional brasileira, outro dispositivo legal de grande expressão nacional que faz menção ao direito à educação básica é o Estatuto da Criança e do Adolescente, Lei no 8.069 de 13 de julho de 1990, que em seu Artigo 53 dita:

A criança e o adolescente têm direito à educação, visando ao pleno desenvolvimento de sua pessoa, preparo para o exercício da cidadania e qualificação para o trabalho, assegurando-se lhes:

I - igualdade de condições para o acesso e permanência na escola;

II - direito de ser respeitado por seus educadores;

III - direito de contestar critérios avaliativos, podendo recorrer às instâncias escolares superiores;

IV - direito de organização e participação em entidades estudantis;

V - acesso à escola pública e gratuita próxima de sua residência.

(Revogado)

V - acesso à escola pública e gratuita, próxima de sua residência, garantindo-se vagas no mesmo estabelecimento a irmãos que frequentem a mesma etapa ou ciclo de ensino da educação básica. (Redação dada pela Lei no 13.845 , de 2019)

Parágrafo único. É direito dos pais ou responsáveis ter ciência do processo pedagógico, bem como participar da definição das propostas educacionais. (BRASIL, 1990).

Há de se mencionar, ainda, a Lei de Diretrizes e Bases da Educação Nacional (LDB, Lei 9394/96) que estabelece, regulamenta e organiza toda a estrutura educacional do país desde 1996. 


\section{0 atendimento educacional de pessoas com Síndrome de Down no Estado do Pparaná em contraponto com a Política Nacional de Educação Especial na perspectiva da Educação Inclusiva}

Art. $4^{\circ} \mathrm{O}$ dever do Estado com educação escolar pública será efetivado mediante a garantia de:

I - educação básica obrigatória e gratuita dos 4 (quatro) aos 17 (dezessete) anos de idade, organizada da seguinte forma: (Redação dada pela Lei no 12.796, de 2013)

a) pré-escola; (Incluído pela Lei no 12.796 , de 2013)

b) ensino fundamental; (Incluído pela Lei no 12.796, de 2013)

c) ensino médio; (Incluído pela Lei no 12.796, de 2013)

Embora a legislação citada anteriormente contemple o atendimento educacional de pessoas com Síndrome de Down de uma maneira geral, este estudo concentra-se na educação básica oferecida à alunos com necessidades educacionais.

Portanto, destaca-se que, atualmente, o Estado do Paraná tem o subsidio de matrícula e modelos de atendimentos desta parcela de estudantes fundamentados em duas propostas legais distintas, a saber a seguir:

A Política Nacional de Educação Especial na Perspectiva da Educação Inclusiva, que tem como objetivo o acesso, a participação e a aprendizagem dos alunos com deficiência, transtornos globais do desenvolvimento e altas habilidades/superdotação nas escolas regulares, orientando os sistemas de ensino para promover respostas às necessidades educacionais especiais, regulamentado pelo decreto nº 6.571, de 17 de setembro de 2008, do MEC - Ministério da Educação e Cultura.

E, a organização das Escolas de Educação Básica, na Modalidade Educação Especial, para oferta da Educação Infantil, do Ensino Fundamental - Anos iniciais ( $1^{\circ}$ e $2^{\circ}$ anos), da Educação 


\section{0 atendimento educacional de pessoas com Síndrome de Down no Estado do Pparaná em contraponto com a Política Nacional de Educação Especial na perspectiva da Educação Inclusiva}

de Jovens e Adultos - Fase I e da Educação Profissional, elaborado pelo pelo Conselho Estadual de Educação do Paraná e aprovada pelo Parecer CEE/CEB no 108/10, de 11/02/10 parecer 007/2014. Diretriz, essa, implementada pela Secretaria Estadual de Educação do Paraná, SEED/PR.

A proposta destina-se a alunos com Deficiência Intelectual, Deficiências Múltiplas e Transtornos Globais do Desenvolvimento (...) Mais do que uma mudança no registro escolar dos alunos, essa alteração na organização curricular tem impacto significativo no reconhecimento do aprendizado dos alunos (...)Dessa forma, o mecanismo proposto de avaliação e certificação elimina o sentimento negativo que a reprovação gera nos alunos e em suas famílias e estimula a continuidade do processo educativo, na proporção em que valoriza o aprendizado obtido, segundo o tempo de cada aluno. (PARANÁ, 2014)

Entende-se, ainda, que comparar e analisar as divergências de ambas as propostas de atendimento de pessoas com Síndrome de Down matriculadas no ensino público paranaense requer alguns cuidados, afinal, para analisar políticas públicas é necessário levar em consideração a eficácia e a eficiência de dada política, como observa Barreira e Carvalho:

A avaliação de eficácia é, por natureza, uma avaliação de processo (...) A eficiência diz respeito às qualidades de um programa, examinados sob os parâmetros técnicos, de tempo e de custos. (BARREIRA e CARVALHO, p. 36, 2001)

Assim sendo, sob o ponto de vista destes autores acima citados, quando analisarmos a eficácia do 


\section{0 atendimento educacional de pessoas com Síndrome de Down no Estado do Pparaná em contraponto com a Política Nacional de Educação Especial na perspectiva da Educação Inclusiva}

programa legal questões como fatores de ordem material, e, sobretudo institucionais empregados como condicionantes positivos ou negativos do desempenho do programa deverão ser respondidos.

Já, quando as avaliações estiverem sob o viés da efetividade do programa legal, os objetivos e metas, impactos e efeitos, alterações de realidades sob o efeito de determinado programa, é que deverão ser analisados. "Logo, a efetividade significativa as quantidades e/ou os níveis de níveis de qualidade com que o programa atinge os impactos e promove os efeitos, previsíveis ou não". (BARREIRA e CARVALHO, p. 36, 2001)

Entende-se, portanto que o grau de satisfação dos usuários dos programas legais é um dos fatores a serem considerados nas análises de efetividade de políticas públicas.

Neste sentido, Gouveia e Souza (2013) trazem para a discussão como critérios de avaliação da efetividade de uma política pública conceitos subjetivos e estruturais, próprios de determinadas sociedades, como noções de justiça e direito, além da noção de desenvolvimento humano, entendendo a educação como uma prática essencialmente histórica e social, diretamente impactados pela política a qual estão submetidos.

(...) é possível se avaliar a efetividade também a partir da ideia de qualidade da oferta para realizar a promessa do pleno desenvolvimento humano, o que significa ponderar que condições objetivas de oferta e permanência no sistema de educação e, ao mesmo tempo, que condições subjetivas de construção da experiência de cada um dos estudantes no espaço educacional compõem o sentido de qualidade em cada tempo histórico específico (DOURADO et al., 2007 apud GOUVEIA e SOUZA, 2013). 


\section{0 atendimento educacional de pessoas com Síndrome de Down no Estado do Pparaná em contraponto com a Política Nacional de Educação Especial na perspectiva da Educação Inclusiva}

Entender, portanto, o desenvolvimento humano de pessoas com Síndrome de Down, e, por consequência Deficiência Intelectual, com todas as características próprias desta condição humana, está intimamente relacionado com a constatação dos impactos e mudanças observadas na vida destes educandos a partir do programa educacional frequentado. É neste sentido, por fim, que as análises das políticas públicas elencadas ao longo deste projeto de pesquisa serão observadas e analisadas.

\section{Referências}

BARREIRO, M. C. R. N. \& CARVALHO, M. C. B. Tendências e perspectivas na avaliação de políticas e programas sociais. São Paulo: IEE/PUC-SP, 2001. Disponível em: https:// marialuizalevi.files.wordpress.com/2015/05/draibe-arretche.pdf. Acesso em 10/08/2021

BRASIL. Lei de Diretrizes e Bases da Educação Nacional. Disponível em: http:/ /www.planalto. gov.br/ccivil_03/Leis/L9394.htm

BRASIL. Constituição (1988). Constituição da República Federativa do Brasil. Brasília, DF: Centro Gráfico, 1988.

BRASIL. Estatuto da Criança e do Adolescente. Disponível em: https://www.jusbrasil.com.br/ topicos/10611702/artigo-53-da-lei-n-8069-de-13-de-julho-de-1990

CURY, C. R. J.; FERREIRA, L.A.M. Justiciabilidade no campo da educação. Revista Brasileira de Administração da Educação, v. 26, p. 75-104, 2010. Disponível em: http://seer.ufrgs.br/index. $\mathrm{php} / \mathrm{rbpae} /$ article/view/19684/11467 


\section{0 atendimento educacional de pessoas com Síndrome de Down no Estado do Pparaná em contraponto com a Política Nacional de Educação Especial na perspectiva da Educação Inclusiva}

CANNING, C.D. PUESCHEL, S. M. Expectativas de desenvolvimento: visão panorâmica. In: PUESCHEL, S. M. (Org) Síndrome de Down, guia para pais e educadores. 8 ed. Campinas, SP: Papirus, 2003, p. 105-114.

GOUVEIA, A. B. \& SOUZA, A. R. Efetividade para o Ensino Fundamental em municípios brasileiros. Disponível em https://www.scielo.br/j/cp/a/YBDyVqMRbHvQJnGMvHffjVz/ abstract/?lang=pt. Acesso em 10/08/2021

LUDKE, M. \& ANDRÉ, M. D. A. Pesquisa em Educação: Abordagens Qualitativas. São Paulo. EPU. 1986.

MINISTÉRIO DA EDUCAÇÃO. Secretaria de Educação Especial (SEESP). Política Nacional de Educação Especial na Perspectiva da Educação Inclusiva. Brasília: MEC/SEESP, 2008.

MOREIRA, L. C; BAUMEL, R. C. Currículo em Educação Especial. Educar em revista, Curitiba, v. I, n. 17, p. 125-137, 2001.

PARANÁ, CONSELHO ESTADUAL DE EDUCAÇÃO. PARECER CEE/CEIF/CEMEP 07/14, de 07 de maio de 2014. Proposta de Ajustes na Organização das Escolas de Educação Básica, na Modalidade Educação Especial, para oferta da Educação Infantil, do Ensino Fundamental - Anos iniciais ( $1^{\circ}$ e $2^{\circ}$ anos), da Educação de Jovens e Adultos Fase I e da Educação Profissional. Disponível em http://www.educadores.diaadia.pr.gov.br/ arquivos/File/ed_especial/parecer_07_14.pdf. Acesso em 10/08/2021.

PAN, M. Abordagens, características, métodos, técnicas e recursos para o trabalho na área de deficiência mental. Curitiba, PR: IBPEX, 2004. Mimeo. 


\section{0 atendimento educacional de pessoas com Síndrome de Down no Estado do Pparaná em contraponto com a Política Nacional de Educação Especial na perspectiva da Educação Inclusiva}

VYIGOTSKI, L. S. A Formação social da mente. São Paulo: Martins Fontes, 1998.

WERNECK, C. Muito prazer, eu existo: um livro sobre o portador de Síndrome de Down. São Paulo, SP: Moderna, 1992. 